$$
\text { Sciencedirect }
$$

Materials Today: Proceedings 5 (2018) 25933-25938

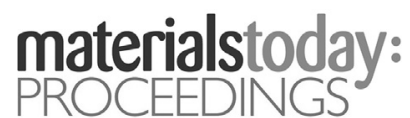

www.materialstoday.com/proceedings

\title{
Properties of carbon coatings obtained by pulsed high power methods of vacuum-arc and magnetron sputtering
}

\author{
Alexander I. Poplavsky*, Alexander Ya. Kolpakov, Marina E. Galkina, \\ Marina G. Kovaleva, Maksim N. Japrintsev, Maksim V. Mishunin, Jeanne V. Gerus \\ Belgorod State National Research University, Belgorod, 308015, Russia
}

\begin{abstract}
Investigation results of the structure, mechanical, tribological and adhesion characteristics of carbon coatings obtained by two different methods: high-power impulse magnetron sputtering (HiPIMS) and pulsed cathodic arc deposition (PCAD) are presented. Coatings obtained by PCAD demonstrated higher hardness and tribological characteristics, but lower adhesion and higher internal stresses. The defectiveness of coatings deposited by both methods is almost the same.

(C) 2018 Elsevier Ltd. All rights reserved.

Selection and peer-review under responsibility of the 11th International Conference "Carbon: Fundamental Problem, Material Science,

Technology".
\end{abstract}

Keywords: DLC; a-C; ta-C; HiPIMS; PCAD; Raman spectroscopy; hardness; adhesion

\section{Introduction}

The first work to obtain a diamond-like carbon coating (DLC) is the study by Eisenberg and Shabo [1], where they described the apparatus for obtaining a DLC coating from an ion beam. The method of obtaining DLC by vacuum-arc sputtering of graphite, developed in 1980 by Soviet scientists headed by V.G. Padalka., is widespread [2]. In the literature this method is known as FCVA (filtered cathodic vacuum arc). At the same time, another group of researchers, led by A.I. Maslov was developed a pulsed vacuum-arc method for obtaining DLC, which allowed to obtain high hardness coatings without the applying of an accelerating potential to the substrate, and equipment for

\footnotetext{
* Corresponding author. Tel.: +7(4722)245608.

E-mail address: poplavsky@bsu.edu.ru
} 
its implementation [3]. However, the publication [3] appeared in the open press only in 1985, when the serial production of the installation for the implementation of this method (UVNIPA-1-001) began. In the literature this method is known as PCAD (pulsed cathodic arc deposition).

At present, studies related to the possibility of using HiPIMS (high-power impulse magnetron sputtering) to obtain DLC [4-6] are carried out, taking into account the positive experience of using this method in the production of hard coatings based on metal nitrides [7]. The main advantage of the HiPIMS method over the arc deposition methods of metallic coatings and metal nitrides is the absence of a drop phase, which makes it possible to obtain smoother and more uniform coatings.

The aim of this work is to compare the properties of carbon coatings obtained by PCAD and HiPIMS methods. This direction has a scientific and practical interest, since these methods use two fundamentally different mechanisms for generating a carbon plasma (a cathode spot of a vacuum arc and cathode sputtering by gas ions).

\section{Experimental techniques, results and discussion}

Carbon coatings of $\sim 1 \mu \mathrm{m}$ thickness were deposited in vacuum on polished substrates made from an instrumental hard alloy based on tungsten carbide with a cobalt binder. Prior to the deposition the vacuum chamber was evacuated to a pressure of $4 \times 10^{-3} \mathrm{~Pa}$ and the substrate surface was cleaned with argon ions using a gas ion source at the following conditions: discharge voltage of $2 \mathrm{kV}$; discharge current of $100 \mathrm{~mA}$; argon pressure of $0.5 \mathrm{~Pa}$; negative bias voltage on the substrate of $2 \mathrm{kV}$; cleaning time of $10 \mathrm{~min}$. Technological parameters of the HiPIMS method: argon pressure in the chamber of $0.6 \mathrm{~Pa}$; balanced discharge mode with power stabilization of $1.8 \mathrm{~kW}$; discharge voltage of $900-1000 \mathrm{~V}$; pulse duration of $60 \mu \mathrm{s}$; pulse repetition rate of $4 \mathrm{kHz}$; the average discharge current of $1.8-2.0 \mathrm{~A}$; negative bias voltage on the substrate of $150 \mathrm{~V}$; distance cathode/substrate of $90 \mathrm{~mm}$; deposition rate of $30 \mathrm{~nm} / \mathrm{min}$. Technological parameters of the PCAD method: chamber pressure of $8 \times 10^{-3} \mathrm{~Pa}$; discharge pulse amplitude of $1 \mathrm{kA}$; pulse duration of $1.2 \mathrm{~ms}$; the discharge voltage of $300 \mathrm{~V}$; pulse repetition rate of $3 \mathrm{~Hz}$; negative bias voltage was not applied to the substrate (floating potential); instantaneous deposition rate of 1.8 $\mathrm{nm} /$ pulse. The temperature of the substrate during the deposition of the above methods did not exceed $70{ }^{\circ} \mathrm{C}$. The cathodes were made of graphite of the grade MPG-6.

The structure was studied by Raman spectroscopy using the "LabRAM HR Evolution" spectrometer, with a laser radiation length of $532 \mathrm{~nm}$ and a power of $50 \mathrm{~mW}$ (Fig. 1). All carbons show common features in their Raman spectra in the $900-2000 \mathrm{~cm}^{-1}$ region: the $\mathrm{G}$ and D peaks, which lie at ca. 1560 and $1360 \mathrm{~cm}^{-1}$, respectively, for visible excitation. The $\mathrm{G}$ and $\mathrm{D}$ peaks are due to $\mathrm{sp}^{2}$ bonded carbon atoms. The $\mathrm{G}$ peak is due to the bond stretching of all pairs of $\mathrm{sp}^{2}$ atoms in both rings and chains. The $\mathrm{D}$ peak is thus due to the breathing modes of $\mathrm{sp}^{2}$ atoms in rings. Characteristic G and D peaks of carbon were fitted using the Breit-Wigner-Fano (BWF) and Lorentzian fits, respectively. The spectra were analyzed by the position of the $D$ and $G$ peaks, the ratio of their intensities $I(D) / I(G)$ and also by the value of $\mathrm{FWHM}(\mathrm{G})$ according to the model describing the three stages of carbon materials structure changing [8]:

1. ideal graphite $\rightarrow$ nanocrystalline graphite (nc-G);

2. nanocrystalline graphite (nc-G) $\rightarrow$ amorphous carbon (a-C);

3. amorphous carbon $(\mathrm{a}-\mathrm{C}) \rightarrow$ tetrahedral amorphous carbon (ta-C).

According to the Raman spectra for HiPIMS coatings, $\operatorname{Pos}(\mathrm{G})=1575 \mathrm{~cm}^{-1}, \operatorname{FWHM}(\mathrm{G})=143 \mathrm{~cm}^{-1}$, $\operatorname{Pos}(\mathrm{D})=1359 \mathrm{~cm}^{-1}, \mathrm{I}(\mathrm{D}) / \mathrm{I}(\mathrm{G})=0.97$. These parameters correspond to stage (2), therefore, the structure of the coating obtained by the HiPIMS method is an intermediate state between nc-G and a-C, in which the fraction of the $\mathrm{sp}^{2}$ phase is greater than $80 \%$, and the size of the $\mathrm{sp}^{2}$ clusters is about $1.3 \mathrm{~nm}$. The spectrum of PCAD coatings is well described by a single function of BWF, without the use of Lorentzian, respectively, $I(D) / I(G)=0$, $\operatorname{Pos}(\mathrm{G})=1557 \mathrm{~cm}^{-1}, \mathrm{FWHM}(\mathrm{G})=279 \mathrm{~cm}^{-1}$. The structure of the PCAD coating is ta-C with a sp $\mathrm{sp}^{3}$-phase fraction of about $85 \%$. The percentage of $\mathrm{sp}^{2}, \mathrm{sp}^{3}$ - phases is indicated on the basis of the model used [8].

In the Raman spectrum of the ta-C coating produced by the PCAD method, the origin of the broad band at about $500 \mathrm{~cm}^{-1}$ is of particular interest. A similar band is also observed in the spectra of nanocrystalline diamond with a crystallite size of less than $10 \mathrm{~nm}$, where this appearance is associated with amorphous carbon in the $\mathrm{sp}^{3}$ state [9]. 

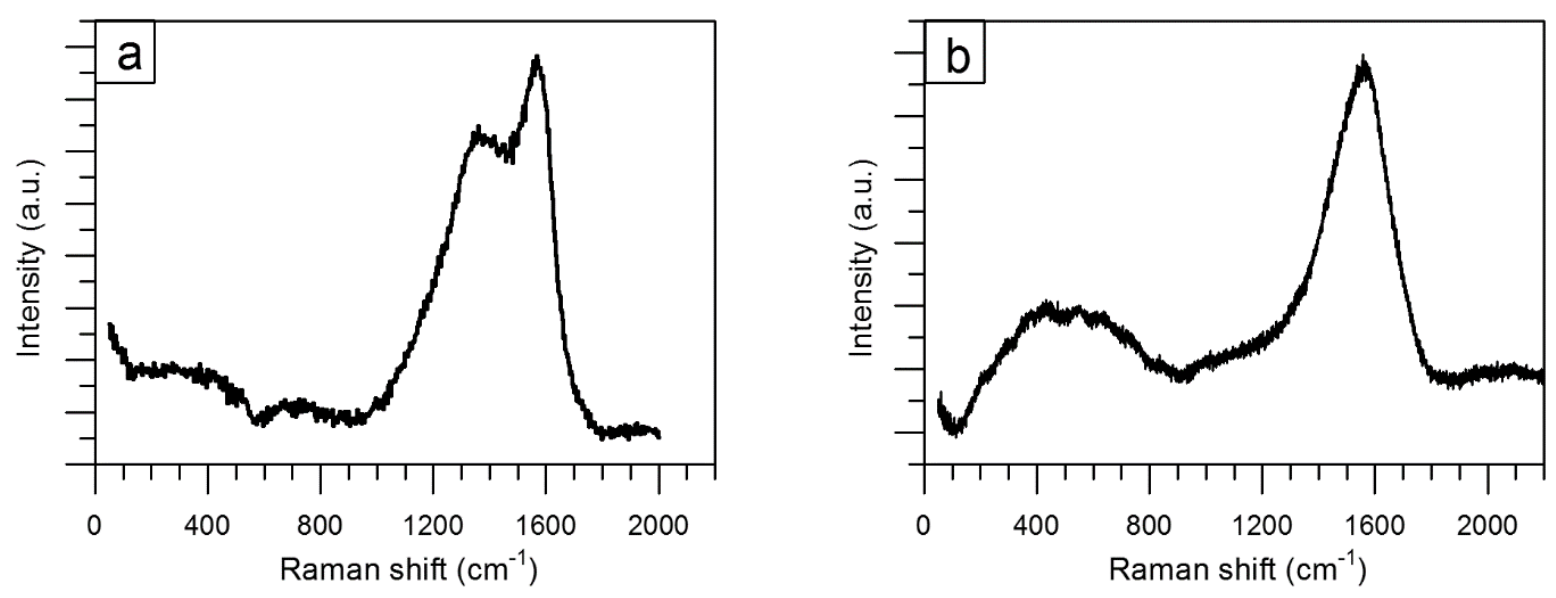

Fig. 1. Raman spectra of carbon coatings obtained by HiPIMS (a) and PCAD (b).

It was established on the basis of modelling that the $\sim 500 \mathrm{~cm}^{-1}$ peak is not associated with the combination oscillations of diamond nanocrystallites; according to the authors, it is caused by defects, surface structures, amorphous materials or any other non-diamond materials [10]. Based on modelling, a band of about $500 \mathrm{~cm}^{-1}$ is attributed to transverse carbon vibrations in the form of carbine-like $\mathrm{sp}^{1}$ - chains ordered in a hexagonal structure with an inter-chain distance of about $0.5 \mathrm{~nm}$, called linear-chain carbon (LCC) [11]. In this case, the $\sim 2000 \mathrm{~cm}^{-1}$ band characteristic of carbyne in the LCC film spectrum has a relatively low intensity. The ab initio calculations the resonant Raman spectra of ta-C were carried out in [12], from which it follows that in the visible region of laser radiation the Raman spectrum arises from $\mathrm{sp}^{2}$ bonded carbon atoms. Ab initio calculations also show that the $\mathrm{sp}^{3}-$ phase can only be seen by using UV excitation above $4 \mathrm{eV}$, confirming the assignment of the T peak at $\sim 1060 \mathrm{~cm}^{-1}$, seen only in UV Raman measurements, to $\mathrm{C}-\mathrm{C} \mathrm{sp}{ }^{3}$ vibrations. It is also worth noting the presence of two weak broad bands $\sim 300 \mathrm{~cm}^{-1}$ and $\sim 700 \mathrm{~cm}^{-1}$ in the low-frequency region of the spectrum of the carbon coating obtained by the HiPIMS method. We associate the appearance of bands in the low-frequency region of the Raman spectrum (below $800 \mathrm{~cm}^{-1}$ ) with $\mathrm{sp}^{2}$ bonded carbon atoms. These bands can be an additional indicator of the amorphous carbon structures ordering degree, their intensity increases with the disordering and decreases with the ordering.

Table 1 shows the investigation results of mechanical and tribological characteristics, as well as the values of surface roughness degree. The hardness $\left(H_{I T}\right)$ and the modulus of elasticity $\left(E_{I T}\right)$ were determined by the method of "instrumental indentation" (ISO 14577-1) on the Shimadzu DUH-211S dynamic microhardnesser at a load of $100 \mathrm{mN}$. The ratio of the indenter penetration depth to the coating thickness during the tests was more than $0.4 \mu \mathrm{m}$. Experimentally measured $H_{I T}$ and $E_{I T}$ are not true values of hardness and modulus of elasticity of the coating, they reflect the characteristics of the "base + coating" system. The hardness of the "base + HiPIMS" system is even lower than the hardness of the base without coating, which confirms our conclusion that the coating structure is an a-C matrix with $\mathrm{sp}^{2}$ - clusters embedded in it.

Table 1. Characteristics of HiPIMS and PSAD coatings, and the characteristics of the base - hard alloy without coating. $H_{I T}$ and $E_{I T}-$ hardness and modulus of elasticity, measured at a load of $100 \mathrm{mN} ; \sigma-$ internal stresses; $k_{s}$ and $k_{300}-$ initial and after $300 \mathrm{~m}$ of the path friction coefficients; $l$ is the friction path up to the complete wear of the coating; $R_{a}$-arithmetical mean deviation of the surface profile.

\begin{tabular}{lllllll}
\hline Sample & $H_{I T}(\mathrm{GPa})$ & $E_{I T}(\mathrm{GPa})$ & $\sigma(\mathrm{GPa})$ & $k_{s}$ & $k_{300}$ & $l(\mathrm{~m})$ \\
\hline Base - hard alloy & 21.9 & 590 & - & - & - & - \\
Hard alloy with HiPIMS coating & 16.2 & 229 & 4.7 & 0.27 & 0.31 & 190 \\
Hard Alloy with PCAD coating & 43.6 & 522 & 10.5 & 0.15 & 0.19 & 50 \\
\hline
\end{tabular}

The value of the internal stresses $(\sigma)$ was calculated using the Stoney formula. The deflection radius of the cantilever beam before and after deposition of the coating was determined by the laser-optical method, the principal scheme of which is described in [13]. The internal stresses of the HiPIMS coatings are half that of the PCAD 
coatings, but their magnitude is high enough for a structure with a predominance of $\mathrm{sp}^{2}$ bonded carbon atoms, that may be associated with features of the HiPIMS method.
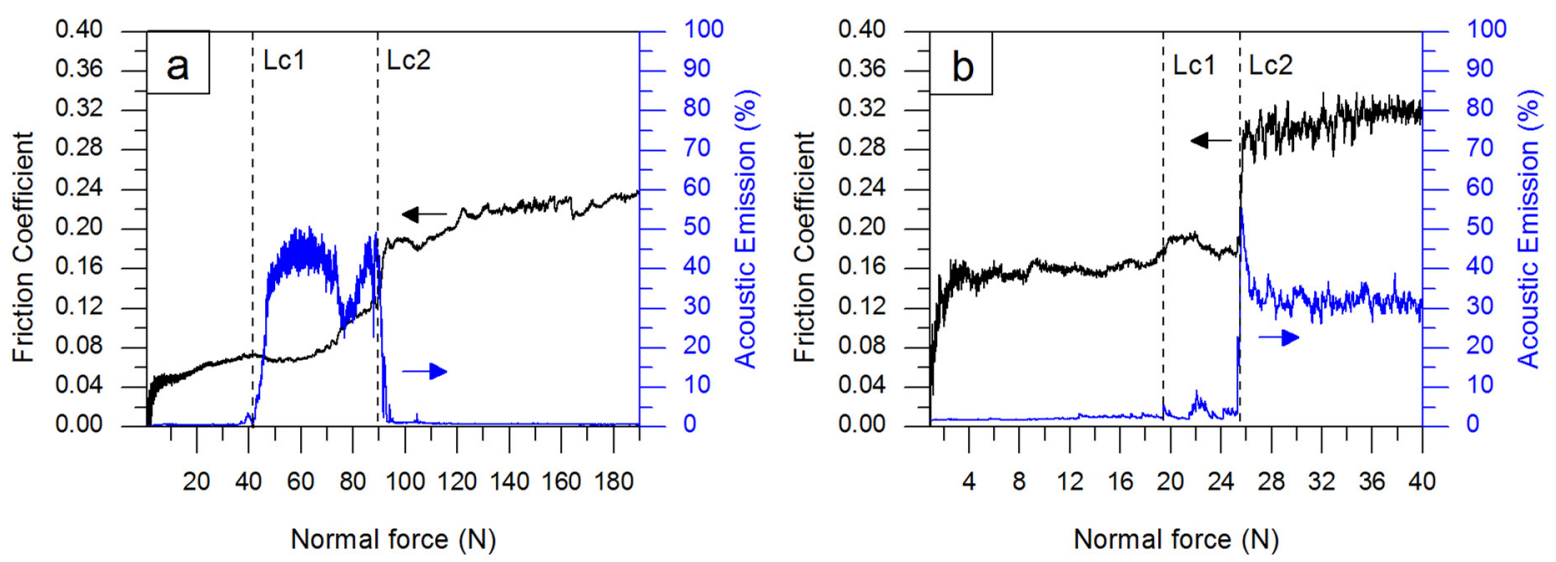

Fig. 2. Scratch testing results of carbon coatings obtained by HiPIMS (a) and PCAD (b) methods.

Tribological testing of the samples was carried out on a laboratory bench according to the "rotating disk-flat stationary sample" scheme and dry friction condition. The counterbody was a $10 \mathrm{~mm}$ diameter disc made of $12 \mathrm{X} 18 \mathrm{H} 10 \mathrm{~T}$ stainless steel. The load on the disk was $50 \mathrm{~g}$, the relative slip velocity was $0.5 \mathrm{~m} / \mathrm{s}$. Comparing the values of the friction coefficients of the initial $\left(k_{s}\right)$, after $300 \mathrm{~m}$ of the path $\left(k_{300}\right)$, and also the friction path up to the complete wear of the coating $(l)$ (see Table 1), it can be stated that the tribological characteristics of the HiPIMS coatings are inferior to those of the PCAD coatings significantly. The wear resistance of the HiPIMS coating is an order of magnitude lower than that of the PCAD coating. Also, both types of coatings have approximately the same values of the arithmetic mean deviation of the surface profile $\left(R_{a}\right)$ measured by the Surtronic 25 profilometer in accordance with ISO 4287: 1997.

The adhesion strength of coatings was determined by the sclerometry technique on the REVETEST scratch-tester of CSM Instruments. The indenter was a Rockwell diamond cone with a rounded sharp end with a radius of $200 \mu \mathrm{m}$. The moment of adhesion failure of the coating was fixed after the tests visually by means of an optical microscope, as well as by the acoustic emission changing and the friction coefficient changing. Fig. 2 shows the results of adhesion tests. At a load of Lc1 $\approx 40 \mathrm{~N}$ on the surface of HiPIMS coated sample there are local areas of peeling of the coating (chips) accompanied by a burst of acoustic emission. At a load of Lc $2 \approx 90 \mathrm{~N}$ the acoustic emission signal drops to zero, and the friction coefficient sharply increases as a result of the complete peeling of the HiPIMS coating. On a PCAD-coated sample, cracks appear at a load of Lc1 $\approx 20 \mathrm{~N}$, and at load of Lc2 $\approx 26 \mathrm{~N}$ adhesion loss occurs, the destruction of the coating is accompanied by a burst of acoustic emission. Thus, in the scratch test, the HiPIMS coating showed a significantly higher adhesive strength than that of the PCAD coating. This fact is explained by the structural difference coatings. Due to the large content of the $\mathrm{sp}^{3}$ - phase, the PCAD coating has high hardness and elastic modulus values, but it is fragile. In contrast, the predominance of $\mathrm{sp}^{2}$ - hybridized carbon in the HiPIMS coating makes it more elastic, which has a favorable effect on its adhesion characteristics. In addition, in scratch tests, the friction coefficient of HiPIMS coatings is lower than that of PCAD coatings, which is associated with the formation of a graphite-like lubricant between the coating and the diamond indenter as a result of their interaction.

Optical studies of the coating surface were carried out using a Hirox KH-7700 digital microscope (Fig. 3). It can be seen that the HiPIMS method does not completely eliminate microparticles in the cathode sputtering products. Defects caused by the microparticles of the graphite cathode, which are contained in the carbon plasma, are observed on both types of coatings. To quantify the defectiveness, the optical images were analyzed using the Digimizer software package, which allows binarization of the image, and then automatic search and measurement of objects (defects in our case). To reduce the influence of noise and to improve the reliability of the results, the 
analysis took into account objects of size $\geq 4$ pix (448 nm). Fig. 4 shows the distribution of defects in size. The maximum defect size is $8.5 \mu \mathrm{m}$ and $12.3 \mu \mathrm{m}$ for HiPIMS and PCAD coatings, respectively. The specific area of defects was calculated by the formula:

$$
S_{s}=\frac{S_{d}}{S_{o}} \cdot 100 \%
$$

where $S_{d}$ - the total area of all defects, $S_{o}$ - the total area of the investigated area (the area of the optical image). For coatings obtained by HiPIMS and PCAD methods, the specific area of defects is approximately the same and equal to $4.3 \%$ and $4.5 \%$, respectively. The only difference is in the distribution of defects in size.
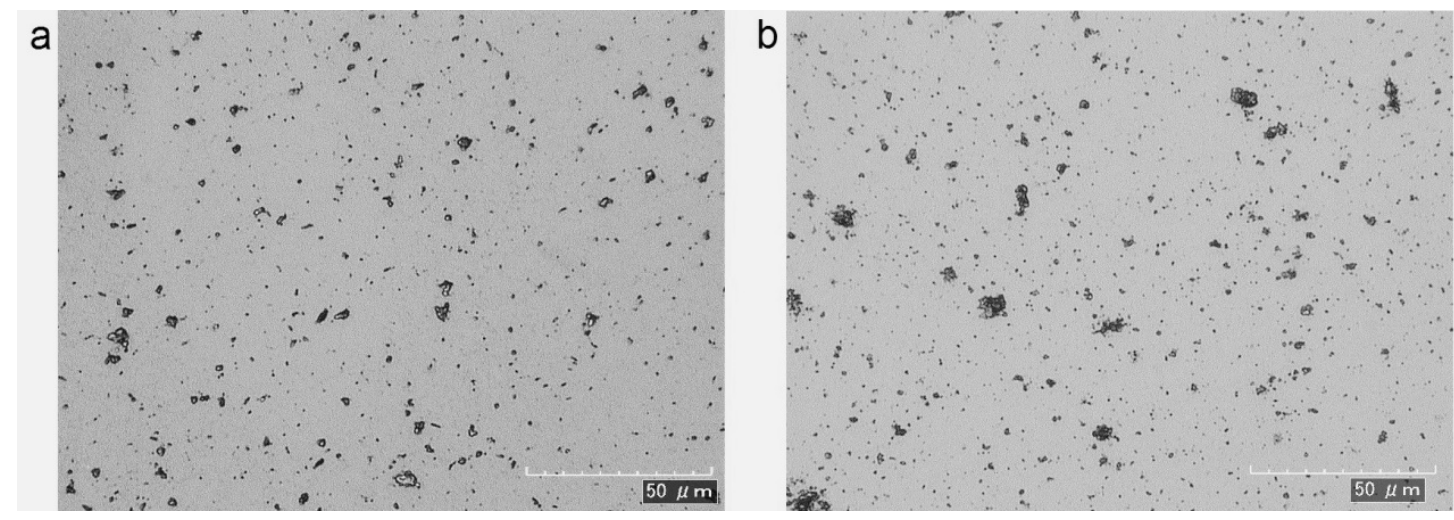

Fig. 3. Optical images of carbon coatings obtained by HiPIMS (a) and PCAD (b) methods.
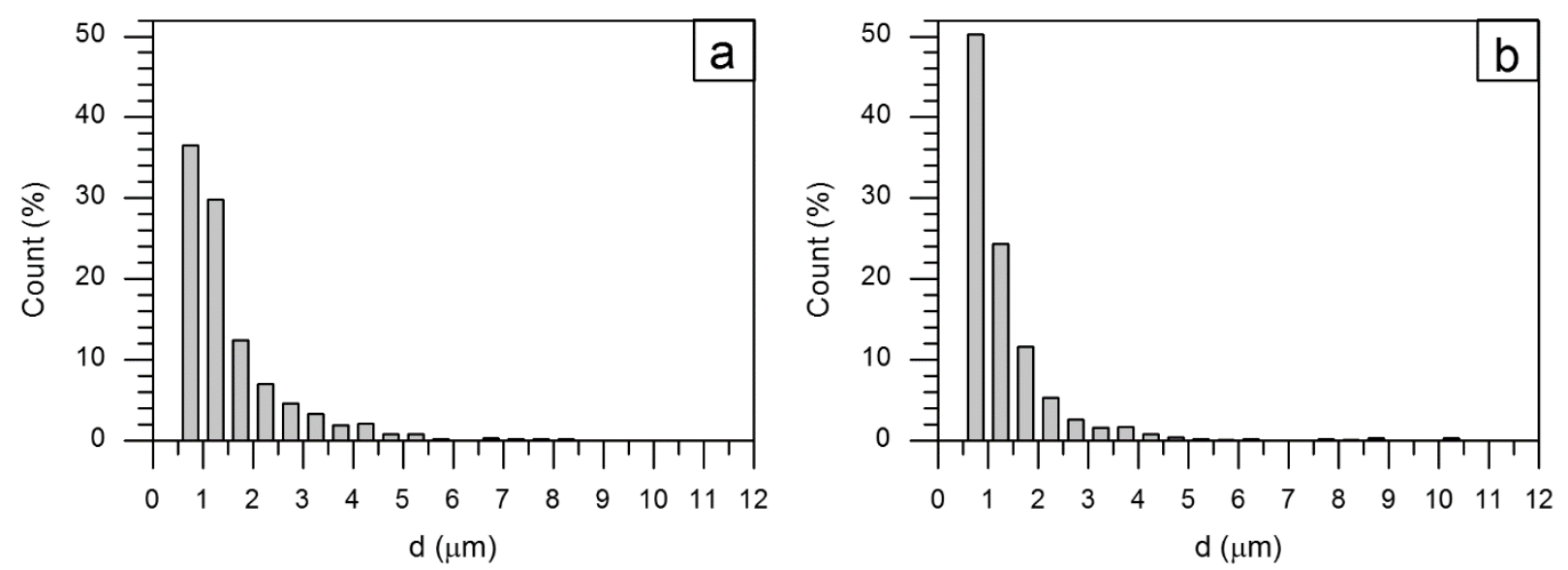

Fig. 4. Distribution of defects in size in coatings obtained by HiPIMS (a) and PCAD (b) methods.

\section{Conclusion}

Thus, it has been established that the carbon coatings obtained by the HiPIMS method are not inferior in properties to the coatings described in $[4,5]$. However, these coatings are significantly inferior to those obtained by the PCAD method for the majority of characteristics (hardness, modulus of elasticity, wear resistance, etc.). The decisive role in this case is played by the ratio of the $\mathrm{sp}^{3}$ - and $\mathrm{sp}^{2}$ - phases in the coatings. The results of analysis of 
Raman spectra showed that the structure of the coating obtained by the HiPIMS method is an intermediate state between $\mathrm{nc}-\mathrm{G}$ and a-C, with the size of $\mathrm{sp}^{2}$ clusters about $1.3 \mathrm{~nm}$. In the ta-C coatings obtained by the PCAD method, the $\mathrm{sp}^{3}$ - phase dominates. Both types of coatings have approximately the same surface roughness and specific defect area. The advantage of coatings obtained by the HiPIMS method is a lower level of internal stresses, in addition, the adhesion characteristics of coatings obtained by the HiPIMS method in this work outperform the similar characteristics of coatings obtained by the PCAD method, therefore a combination of these methods has a scientific and practical interest.

\section{Acknowledgements}

Part of studies was carried out on the equipment of the Joint Research Center of Belgorod State National Research University «Technology and Materials».

\section{References}

[1] S. Aisenberg, R. Chabot, J. Appl. Phys. 42 (1971) 2953-2957.

[2] I.I. Aksenov, V.G. Padalka, V.T. Tolok et al., Sov. J. Plasma Phys. 6 (1980) 504-507.

[3] A.I. Maslov, G.K. Dmitriev, Yu.D. Chistyakov, Prib. Tekh. Eksp. 3 (1985)146-149.

[4] K.V. Oskomov, A.A. Solov'ev, S.V. Rabotkin, Tech. Phys. 12 (2014) 1811-1814.

[5] M. Huang, X. Zhang, P. Ke. et al., Applied Surface Science 283 (2013) 321-326.

[6] F.Li, S. Zhang, J. Kong. et al., Thin Solid Films. 519 (2011) 4910-4916.

[7] A. Anders, J. Appl. Phys 121 (2017) 171101-171175.

[8] A.C. Ferrari, J. Robertson, Phys. Rev. B. 61 (2000) 14095-14107.

[9] S. Tikhomirov, T. Kimstach, Analitika. 1 (2011) 28-32.

[10] J. Filik, J.N. Harvey, N.L. Allan et. al., Phys. Rev. B. 74 (2006) 035423-10.

[11] E.A. Buntov, A.F. Zatsepin, M.B. Guseva et al., Carbon 117 (2017) 271-278.

[12] S. Piscanec , F. Mauri, A.C. Ferrari et al., Diamond Relat. Mater. 14 (2005) 1078- 1083.

[13] A.Ya. Kolpakov, A.I. Poplavsky, M.E. Galkina, et al., Uprochnyayushie technologii I pokrytiya 4 (2012) 40-45. 